Methods Patients diagnosed with vulvar SCC or VC between the years of 2004 and 2016 were identified in the NCDB. OS was assessed with Kaplan-Meier curves and the log-rank test. Construction of a Cox model compared survival after controlling for confounding variables.

Results The reported incidence of SCC of the vulva has significantly increased since $2004(\mathrm{p}<0.0001)$. In contrast, the incidence of VC has remained stable since $2004(\mathrm{p}=0.344)$. Compared to SCC, VC was significantly more likely to be diagnosed in older women $(p<0.0001)$ and treated with surgery alone $(\mathrm{p}<0.0001)$. However, on propensity score weighted analysis there was a trend toward improved OS in women with VC compared to those with SCC ( $p=0.0794)$. Multivariable Cox survival analysis showed an improvement in $\mathrm{OS}$ in VC patients treated with both primary site and regional lymph node surgery compared to primary site surgery alone (HR 0.67, 95\% confidence interval [CI] $0.46-0.97, \mathrm{p}=$ 0.0357).

Conclusions Verrucous carcinoma is more likely to present in women at an older age. Regional lymph node surgery in addition to primary site surgery significantly improves $\mathrm{OS}$ in $\mathrm{VC}$ patients.

\section{EPV289/\#657 EPIDEMIOLOGICAL PROFILE OF PATIENTS WITH MALIGNA VULVA NEOPLASIA ATTENDED AT SANTA MARCELINA ITAQUERA HOSPITAL - SAO PAULO}

${ }^{1} \mathrm{JA}$ Barbosa*, ${ }^{2} \mathrm{M}$ Mesquita, ${ }^{2} \mathrm{~S}$ Sanches, ${ }^{2} \mathrm{C}$ Sousa, ${ }^{2} \mathrm{M}$ Silva, ${ }^{2} \mathrm{M}$ Manchini, ${ }^{2} \mathrm{M}$ Brandão, ${ }^{2} \mathrm{C}$ Gomez, ${ }^{2} \mathrm{~T}$ Almeida. ${ }^{1} \mathrm{Casa}$ de Saúde Santa Marcelina, Gynecology Oncology, Sao Paulo, Brazil; ${ }^{2}$ Casa de Saúde Santa Marcelina, Gynecologic Oncology, Sao Paulo, Brazil

\subsection{6/ijgc-2021-IGCS.360}

Objectives Objective: To study the epidemiological profile of patients diagnosed with vulvar malignancy seen at Santa Marcelina Itaquera Hospital (HSM) in São Paulo.

Methods Analysis of medical records of patients undergoing follow-up at the Gynecology Oncology outpatient clinic between the years 2008 to 2020. The information analyzed were: age, parity, smoking, histological type of the tumor, neoadjuvance, surgical treatment, adjuvance, recurrence, lymph node involvement and death.

Results

Result 45 patients were seen, whose average age was 66 years, which numerically represents $51.11 \%$ of the patients seen; $26.66 \%$ were smokers and the most common histological type is squamous cell carcinoma, marking $82.22 \%$ of all other types identified. Five patients $(11.11 \%)$ were classified as stage I, fifteen (33.33\%) stage II, thirteen (28.88\%) stage III and twelve (26.66) of stage IV patients. Within this scenario, neoadjuvant therapy was part of $60 \%$ of the cases; surgical treatment $80 \%$ and adjuvance $62.22 \%$. Sixty-four percent of the patients did not experience recurrence or disease progression. Forty percent of patients who did surgical procedure with lymphadenectomy had lymph node involvement and twentyfour patients $(53.33 \%)$ died.

Conclusions

Conclusion The epidemiological profile of patients are consistent with the literature, from the age group, histological type, percentage of death and recurrence. The high rate of death is mainly related to late diagnosis, although neoadjuvant treatment allows surgery in advanced cases.

\section{EPV290/\#90 LONG-TERM RESULTS OF PRIMARY VAGINAL CANCER TREATMENT: THE BELARUS NATIONAL CANCER CENTRE EXPERIENCE}

${ }^{1} \mathrm{O}$ Matylevich*, ${ }^{2} \mathrm{H}$ Trukhan, ${ }^{1} \mathrm{E}$ Dolomanova, ${ }^{1} \mathrm{D}$ Rouski, ${ }^{3} \mathrm{O}$ Zubets, ${ }^{1} \mathrm{~S}$ Mavrichev. ${ }^{1} \mathrm{NN}$ Alexandrov National Cancer Centre of Belarus, Gynecologic Oncology Department, Minsk, Belarus; ${ }^{2}$ Belarusian Medical Academy of Postgraduate Education, Department of Oncology, Minsk, Belarus; ${ }^{3}$ NN Alexandrov National Cancer Centre of Belarus, Cancer Control Department, Minsk, Belarus

\subsection{6/ijgc-2021-IGCS.361}

Objectives To study the long-term results of treatment of vaginal cancer (VC) patients and to evaluate the results of diagnosis and treatment of patients living in urban and rural areas.

Methods The data of 70 patients with primary VC treated at NN Alexandrov National Cancer Centre of Belarus from 2000 to 2019 were included. The median age was 64 years (rang, 32-87). Morphology in 91.5\% (64/70) cases was squamous cell cancer, in $7.1 \%(5 / 70)$ - adenocarcinoma, in $1.4 \%$ $(1 / 70)$ - adenosquamous carcinoma. The distribution by the stage was as follows: Stage I in $17(24.3 \%)$ patients, Stage II in $30(42.9 \%)$, Stage III in $12(17.1 \%)$, Stage IV in 11 $(15.7 \%)$ cases. Treatment was performed in $82.8 \%(58 / 70)$ cases: in $94.1 \%(16 / 17)$ for Stage I disease, in $83.3 \%(25 / 30)$ for Stage II, in $91.7 \%(11 / 12)$ for Stage III, and in $54.5 \%$ (6/ 11) for Stage IV.

Results The median follow-up time was 33 months (range, 1220). A total of 42 women died: 28 from progression of VC and 14 from other diseases. Overall survival (OS) was 31.9 $\pm 6.8 \%$, median survival - 41 months (95\% CI 0.0-105.3). Disease-specific survival (DSS) for the entire group was 54.5 $\pm 6.8 \%$, median not reached. The overall survival rate of urban women was $44.8 \pm 10.6 \%$, rural $-22.5 \pm 8.2 \%$, p = 0.142 ; DSS $-57.6 \pm 10.5 \%$ and $53.0 \pm 8.4 \%, \mathrm{p}=0.448$, respectively.

Conclusions The DSS rate was $54.0 \pm 6.8 \%$; the OS rate did not exceed $31.9 \pm 6.8 \%$. Rural residence was not associated with late stage at diagnosis or receipt of treatment.

\section{EPV293/\#425 EFFECT ON OVERALL SURVIVAL OF CANCER PROGRAM-LEVEL VARIATION IN THE USE OF NEOADJUVANT CHEMOTHERAPY FOR ADVANCED OVARIAN CANCER: A DIFFERENCE-IN- DIFFERENCES STUDY}

\begin{abstract}
${ }^{1}$ A Melamed*, ${ }^{2} \mathrm{JA}$ Rauh-Hain, ${ }^{1} \mathrm{~A}$ Gockley, ${ }^{2} \mathrm{R}$ Nitecki, ${ }^{3} \mathrm{P}$ Ramirez, ${ }^{4} \mathrm{D}$ Hershman, ${ }^{5} \mathrm{~N}$ Keating, ${ }^{1} \mathrm{~J}$ Wright. ${ }^{1}$ Columbia University College of Physicians and Surgeons, Gynecologic Oncology, New York City, USA; ${ }^{2}$ University of Texas MD anderson Cancer Center, Gynecologic Oncology, Houston, USA; ${ }^{3}$ University of Texas MD anderson Cancer Center, Gynecologic Oncology and Reproductive Medicine, Houston, USA; ${ }^{4}$ Herbert Irving Comprehensive Cancer Center, Oncology, New York City, USA; ${ }^{5}$ Harvard Medical School, Health Policy, Boston, USA
\end{abstract}

\subsection{6/ijgc-2021-IGCS.362}

Objectives To evaluate the effect of cancer program-level variations in use of neoadjuvant chemotherapy (NACT) on overall survival among patients with advanced ovarian cancer.

Methods We included women with advanced-stage epithelial ovarian cancer treated 2004-2015 in Commission on Canceraccredited cancer programs that began administering NACT liberally or continued to restrict its use after the publication of a randomized trial in 2010. We used flexible parametric survival models to perform a difference-in-differences analysis 